\title{
The educational divide in e-privacy skills in Europe
}

\author{
Maineri, Angelica Maria ${ }^{\text {a }}$; Achterberg, Peter ${ }^{a}$ and Luijkx, Ruud ${ }^{a, b}$ \\ ${ }^{a}$ Department of Sociology, Tilburg University, The Netherlands, ${ }^{b}$ Department of Sociology \\ and Social Research, University of Trento, Italy.
}

\begin{abstract}
This work investigates the educational divide in e-privacy skills in Europe. We ask whether the gap exists at the level of the individuals, and subsequently we seek to frame it in the European context by using the reflexive modernization theory. By using data from the Flash Eurobarometer 443 and implementing multilevel linear regression models, we confirm the presence of an educational divide in Europe, although it is mediated by the frequency of Internet use. Furthermore, the enhancement of e-privacy protecting behaviors is more likely in highly reflexive countries. Yet, there are no differences in terms of the size of the educational divide between countries. The study contributes to the literature on the second-level digital divide by focusing on e-privacy issues. Furthermore, this paper is among the first in adopting a comparative perspective when studying e-privacy issues and shows that in highly reflexive countries the educational digital divide in e-privacy skills does not widen.
\end{abstract}

Keywords: E-privacy; digital divide; reflexive modernization 